\title{
Effect of Anthrobacter creatinolyticus on phytoremediation of arsenic contaminated water by Echinodorus cordifolius
}

\author{
Channratha Prum ${ }^{1}$, Rujira Dolphen ${ }^{2}$ and Paitip Thiravetyan ${ }^{1} *$ \\ ${ }^{1}$ School of Bioresources and Technology, King Mongkut's University of Technology Thonburi, \\ Bangkok 10150, Thailand \\ 2 Pilot Plant Development and Training Institute, King Mongkut's University of Technology \\ Thonburi, Bangkok 10150, Thailand. \\ *Corresponding author: Tel: 024707535, e-mail: paitip.thi@kmutt.ac.th
}

\begin{abstract}
Arsenic (As) contamination in the environment is a worldwide problem. Many technologies such as oxidation, membrane technology, adsorption, electrokinetics, ion exchange have been used to remove As from contaminated water. However, these technologies are required high costs and skillful labor for control and maintenance. Phytoremediation, using plant to remove pollution, is a cost effective and eco-friendly technology. Nevertheless, this technology still brings about limitations such as high phytotoxicity of As. Application of microorganisms to enhance heavy metal removal by plant might be an effective technology. Some plant species such as Echinodorus cordifolius, Cyparus alternifolium, Acrostichum aureum, Coolocasia esculenta, and Echinodorus cordifolius were screened for As removal efficiency. From our screening plants revealed

that E. cordifolius was the highest efficiency species for As removal. Combination between E. cordifolius and microorganisms for As removal was studied. Bacillus subtilis and Anthrobacter creatinolyticus (isolated from arsenic contaminated soil from Nakhon Si Thammarat province) were used to compare As removal efficiency. The result showed that at $1^{\text {st }}$ and $2^{\text {nd }}$ cycle of experiment, As removal was no significantly different between noninoculated E. cordifolius and inoculated $E$. cordifolius. After that at $3^{\text {rd }}$ and $4^{\text {th }}$ cycle of experiments, E. cordifolius inoculated with A. creatinolyticus had the highest As removal efficiency compared to other conditions. This might due to A. creatinolyticus tolerated to As concentration greater than $B$. subtilis. In addition, $A$. creatinolyticus also produced ammonium for enhancing plant growth. Therefore, E. cordifolius inoculated with $A$. creatinolyticus was suitable to apply in As contaminated

water.
\end{abstract}

Keyword: Phytoremediation, Arsenic, Echinodorus cordifolius, Anthrobacter creatinolyticus 


\section{INTRODUCTION}

Arsenic (As) is a toxic metalloid which can pollute water, soil, crops. The presence of As in environments is a worldwide problem. Over 70 countries have problem with As contaminated ground water of an estimated 150 million people. In estimated, 110 million of this people live in south and south-east Asia. In Bangladesh, higher than 100 million people drink water up to $1 \mathrm{mg} / \mathrm{L}$ of As levels that is higher than 100 times the World Health Organization drinking water guideline value (WHO, 2011). As could be found in environment as the result of the dissolution of minerals from volcanic, sedimentary rocks, manufacture of lasers, semiconductors, industry waste, agricultural activities, pharmaceutical products, and human activities (Khang et al., 2012). It is rarely found as its native form because of its bonding affinity with other elements (Islam et al., 2015). In the environment, As exists in many oxidation states - arsenate (As (V)), arsenite (As (III)), arsenic (As (0)), and methyl group of arsenic. Arsenate (As (V)) is the thermodynamically stable state of arsenic in toxic waters, while arsenite (As (III)) predominates in reduced redox conditions (Pell et al., 2013). As is highly toxic to plants and microorganism (Alvarado et al., 2008), especially it can affect human health such as skin damage, increase lung, bladder, and kidney cancers, nerve damage in humans (Molin et al., 2015). According to World Health Organization (WHO, 2011) As standard in drinking water has $0.01 \mathrm{mg} / \mathrm{L}$. The industrial effluent standard of As in Thailand is not more than $0.25 \mathrm{mg} / \mathrm{L}$ (PCD).

There are many techniques used for As remediation such as oxidation, membrane technology, adsorption, electrokinetics, ion exchange, adsorption, and coagulation flocculation(Roy et al., 2015). These techniques can effect to levels of arsenic contaminants and high removal efficiency (Roy et al., 2015). However, these techniques have several drawbacks, principally their technological complexity, high cost, maintenance, and the need skill for technicians (Rahman et al., 2014).

Phytoremediation, a plant-based green technology, can be considered as a simple, effective, and eco-friendly technology for As from water (Rahman et al., 2011). Using some submerged aquatic saprophyte and floating plants in the process of phytoremediation is more commonly known as phytofiltration (Rahman et al., 2011). Moreover, the application of microorganisms to enhance As removal by plant might be an effective technology.

The aim of work is to studies the interaction plant with microorgaism for remove arsenic from water. The aquatic plants such as Echinodorus cordifolius, Cyparus alternifolium, Acrostichum aureum, Coolocasia esculenta, and Echinodorus cordifolius have been selected for a screening to find plant species with the highest As removal efficiency. Bacillus subtilis (Adams, 1973; Giri, et al., 2012) and Arthrobacter creatinolyticus (screened from arsenic contaminated soil at Nakhon Si Thammarat province, Thailand) were selected in this work. In addition, the combination of plant and microorganism will be applied to study As removal from wastewater.

\section{METHODOLOGY}

\section{Screening plants for removal arsenic concentration}

The aquatic plants species such as Echinodorus cordifolius, Cyparus alternifolium, Acrostichum aureum, and Coolocasia esculenta were applied to As remediation. They were washed carefully with tab water to remove any contaminated substances from their roots. The similar weights in each species in triplicate are used for screening.

After plants preparation, each plant was placed in small pots with triplicate for each 
treatment. The arsenic concentration was prepared $2 \mathrm{ppm}$ inside the small pots with water $400 \mathrm{ml}$. The solutions were sampling at time $1,3,5$, and 7 days. The solution was analyzed for amount of remaining As by an inductively coupled plasma spectrophotometer (ICP JY2000).

\section{Phytoremediation of As solution extracted from As contaminated soil}

The research was observed the efficiency of plant E. cordifolius inoculated with microorganism Bacillus subtilis or Anthrobacter creatinolyticus from arsenic solution abtained from arsenic contaminated soil solution. There are many reports revealed that Bacillus subtilis could resistant to high concentrations of arsenic (Adams, 1973; Giri et al., 2012). Meanwhile, Arthrobacter creatinolyticus was screened from arsenic contaminated soil at Nakhon Si Thammarat province; Thailand will be grown in NB and inoculate into treatment conditions. $100-120 \mathrm{~g}$ of E. cordifolius inoculated with $10 \%$ (v/v) $B$. subtilis or A. creatinolyticus were grown in small pot (400 $\mathrm{mL}$ of arsenic solution) and used as treatment. E. cordifolius without inoculation and As contaminated solution extracted from soil were used as control conditions. Initial As concentration was 2 ppm from As contaminated soil solution and the experiment was studied for 4 cycles with 3 days per cycle. All conditions were prepared triplicates for each treatment. As concentrations were through filtered and determined by inductively coupled plasma (ICP JY2000).

\section{Removal efficiency}

Arsenic removal efficiency (\%) for this experiment is defined by the following equation:

$$
\begin{gathered}
\text { As removal }(\%)=\llbracket \frac{C_{\text {control }}-C_{\text {treatment }}}{C_{\text {control }}} \rrbracket X 100 \\
\mathrm{C}_{\text {control }} \text { and } \mathrm{C}_{\text {treatment }} \text { are the arsenic }
\end{gathered}
$$

concentration in the water from control (unplanted) and treatment (planted) small pots, respectively.

\section{Analysis and statistic method}

Data were analyzed by one way analysis of variance (ANOVA) using Statistical Program for Social Science (SPSS) version at 95\% confidence.

\section{RESULTS AND DISCUSSION}

Screening result revealed that $E$. cordifolius had the highest efficiency species for As removal 98\% (TABLE 1). Therefore, $E$. cordifolius was selected to study As removal from water by inoculated with microorganism.

TABLE1. EFFECIENCY OF As REMOVAL BY VARIOUS PLANTS FOR 5 DAYS

\begin{tabular}{|l|c|c|}
\hline Conditions & $\begin{array}{c}\text { As } \\
\text { removal } \\
(\%)\end{array}$ & System pH \\
\hline $\begin{array}{l}\text { As contaminated } \\
\text { wastewater (Control) }\end{array}$ & 13 & $6.86 \pm 0.13$ \\
\hline Acrostichum aureum & 62 & $7.03 . \pm 0.20$ \\
\hline Cyperus alternifolius & 18 & $6.20 \pm 0.43$ \\
\hline Echinodorus cordifolius & 98 & $6.82 \pm 0.07$ \\
\hline Colocasia esculenta & 66 & $6.85 \pm 0.17$ \\
\hline
\end{tabular}

\section{Arsenic removal by $E$. cordifolius} inoculated with $B$. subtilis or $A$. creatinolyticus

The result showed that phytoremediation of arsenic contaminated soil solution with $E$. cordifolius inoculated with A. creatinolyticus had the highest removal efficiency (Fig.1).

In cycle $1^{\text {st }}$ and $2^{\text {nd }}$, the efficiency of As removal showed no significant difference between $E$. cordifolius inoculated with $A$. creatinolyticus conditions, E. cordifolius inoculated with B. subtilis conditions and noninoculated E. cordifolius (Fig.1).

In cycle $3^{\text {rd }}$ of As removal was removed completely by $E$. cordifolius inoculated with A. creatinolyticus. However, the efficiency of arsenic removal by $E$. cordifolius inoculated with $B$. subtilis and non-inoculated $E$. cordifolius were not significantly different (Fig.1). 

ISBN: 978-1-63248-084-2 doi: 10.15224/ 978-1-63248-084-2-93

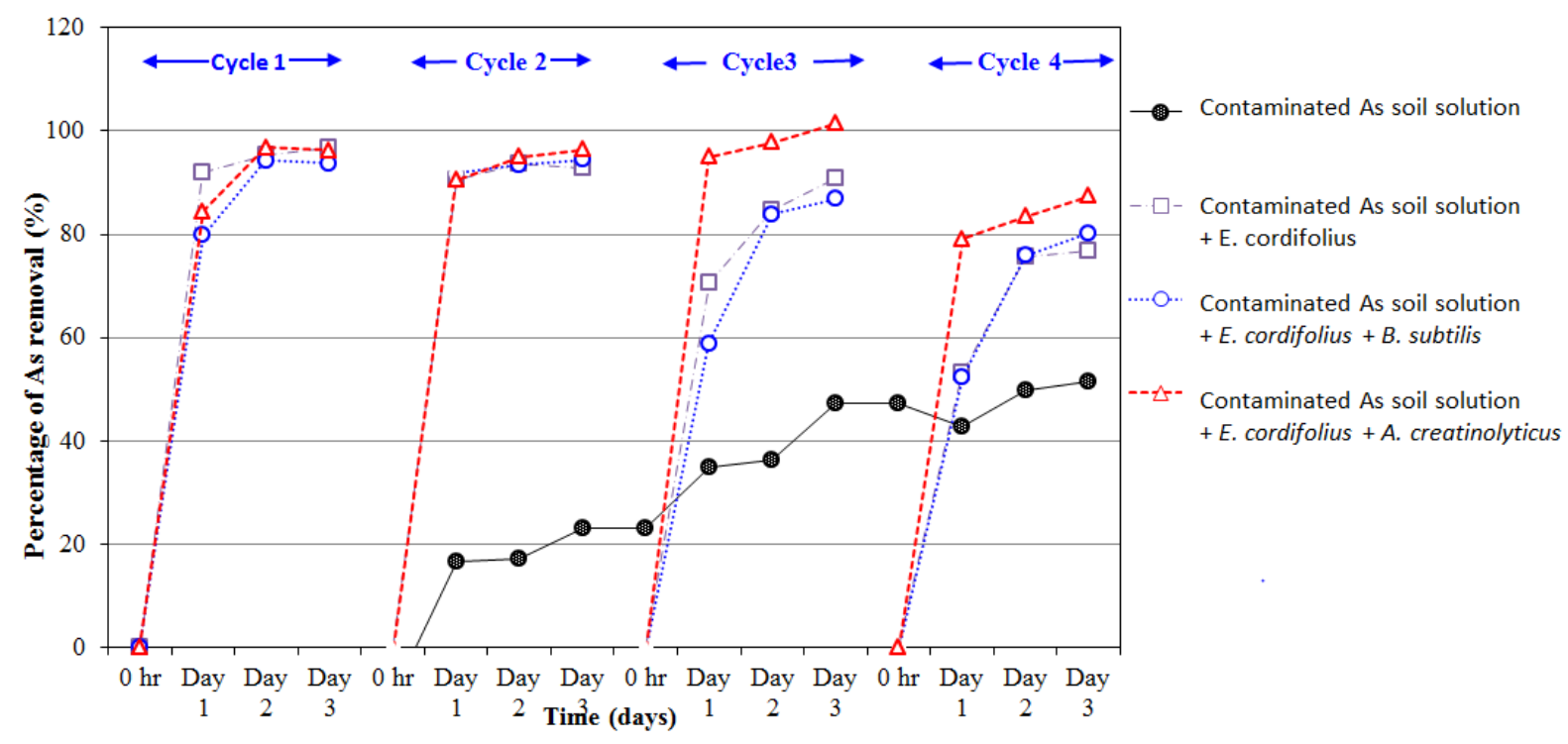

Fig. 1 Percentage of As removal by non-inoculated E. cordifolius, inoculated E. cordifolius with B. subtilis and A. creatinolyticus for 4 cycles

Moreover, the last cycle of the experiment, E. cordifolius inoculated with $A$. creatinolyticus $(87.44 \%)$ have the highest efficiency of As removal, and the efficiency of As removal in E. cordifolius inoculated with A. creatinolyticus was still significantly different compared to other conditions (Fig.1). In this case, A. creatinolyticus tolerated to As concentration greater than B. subtilis. Additionally, A. creatinolyticus might due enhance plant ability for As removal from water by producing ammonium (Fig.2) and plant growth hormone (Indole-3-acetic acid) (Fig.3).

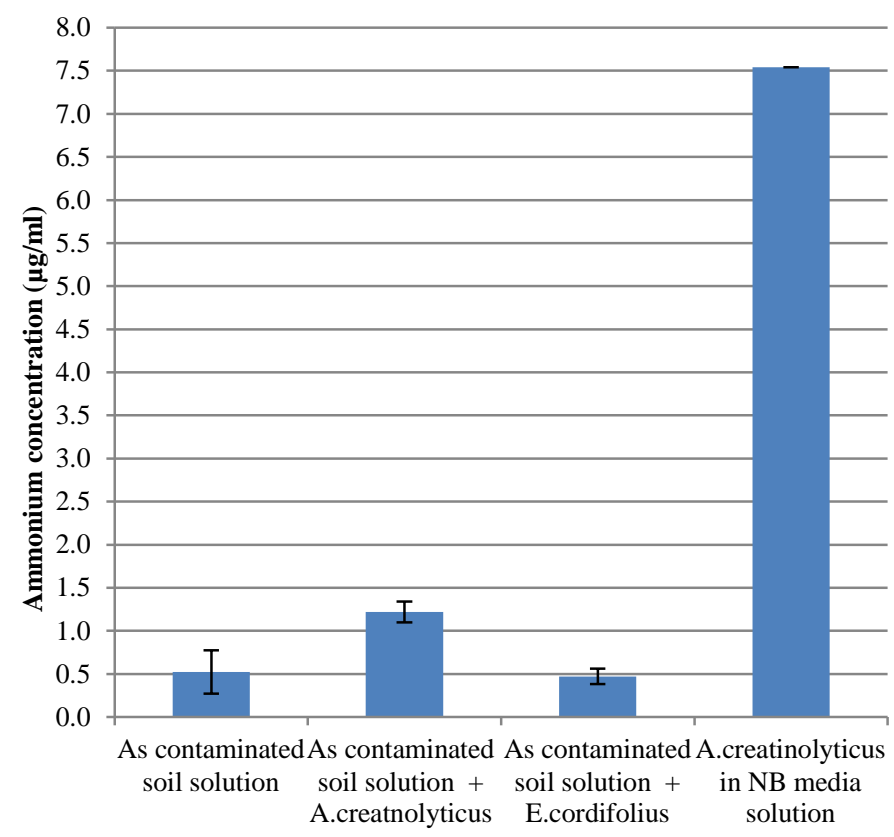

Fig. 2 Ammonium concentration produced from various conditions

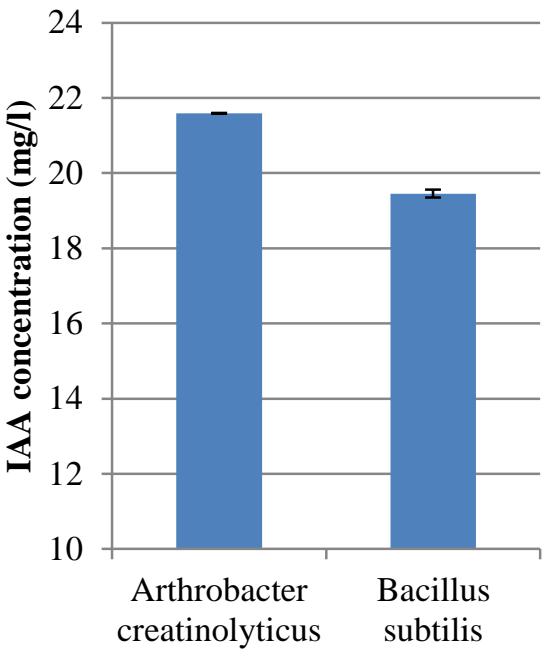

Fig.3 IAA concentration Additionally, in control conditions, As contaminated soil solution was used through 4 cycles of experiment. It was found that natural microorganisms can grow and adsorb As at $2^{\text {nd }}, 3^{\text {rd }}$, and $4^{\text {th }}$ cycle of experiment.

\section{CONCLUSION}

The screening plants of As removal from wastewater were compared the ability of plants. E. cordifolius showed the highest efficiency for As removal. The application of A. creatinolyticus to increase As phytoremediation can be an effective method for arsenic contaminated water treatment. A. creatinolyticus could enhance plant abilities for As removal by producing nitrogen source and Indole-3-acetic acid (IAA) for plant growth. 
Copyright $\odot$ Institute of Research Engineers and Doctors, USA .All rights reserved.

ISBN: 978-1-63248-084-2 doi: 10.15224/ 978-1-63248-084-2-93

\section{Acknowledgment}

The authors would like to thank UNESCO Biotechnology School in Asia for financial support and Assoc. Prof. Dr. Paitip Thyravetyan for advises and guidance.

\section{Reference}

[1]. Alvarado, S., Guédez, M., Lué-Merú, M. P., Nelson, G., Alvaro, A., Jesús, A. C., and Gyula, Z., 2008, Arsenic removal from waters by bioremediation with the aquatic plants Water Hyacinth (Eichhornia crassipes) and Lesser Duckweed (Lemna minor). Bioresource Technology, 99, 8436-8440.

[2]. Favas, P. J. C., Pratas, J., and Prasad, M. N. V., 2012, Accumulation of arsenic by aquatic plants in large-scale field conditions: Opportunities for phytoremediation and bioindication. Science of The Total Environment, 433, 390-397.

[3]. Heijden Van Der, M.G.A., Bardgett, R.D, Van Straalen, N.M., 2008, The unseen majority, soil microbes as drivers of plant diversity and productivity in terrestrial ecosystems. Ecological, 11, 296-310.

[4]. Islam, M. S., Saito, T., and Kurasaki, M., 2015, Phytofiltration of arsenic and cadmium by using an aquatic plant, Micranthemum umbrosum: Phytotoxicity, uptake kinetics, and mechanism. Ecotoxicology and Environmental Safety, 112, 193-200.

[5]. Khang, H. V., Hatayama, M., and Inoue, C., 2012, Arsenic accumulation by aquatic macrophyte coontail (Ceratophyllum demersum L.) exposed to arsenite, and the effect of iron on the uptake of arsenite and arsenate. Environmental and Experimental Botany, $83,47-52$.

[6]. Molin, M., Ulven, S. M., Meltzer, H. M., and Alexander, J., 2015, Arsenic in the human food chain, biotransformation and toxicology - Review focusing on seafood arsenic. Journal of Trace Elements in Medicine and Biology, 31, 249-259.

[7]. Pollution Control Department (PCD): Ministry of Natural Resoursces and Environment.

[8]. Pell, A., Márquez, A., López-Sánchez, J. F., Rubio, R., Barbero, M., Stegen, S., and Díaz-Palma, P., 2013, Occurrence of arsenic species in algae and freshwater plants of an extreme arid region in northern Chile, the Loa River Basin. Chemosphere, 90(2), 556-564.

[9]. Rahman, M. A., and Hasegawa, H., 2011, Aquatic arsenic: Phytoremediation using floating macrophytes. Chemosphere, 83(5), 633-646.

[10]. Rahman, S., Kim, K.-H., Saha, S. K., Swaraz, a. M., and Paul, D. K., 2014, Review of remediation techniques for arsenic (As) contamination: A novel approach utilizing bio-organisms. Journal of Environmental Management, 134, 175-185.

[11]. Roy, M., Giri, A. K., Dutta, S., and Mukherjee, P., 2015, Integrated phytobial remediation for sustainable management of arsenic in soil and water. Environment International, 75, 180-198.

[12]. Wang, Q. C., 2002, Phytoremediation of Pooluted Waters; Potentials and Prospects of Wetland Plants. Engineering in life science, 22, 199200.

[13]. World Health Organization (WHO), 2011, Guidelines for drinking-water quality chemical fact sheets-chemical contaminants in drinking water. 
The Third Intl. Conf. On Advances in Applied Science and Environmental Technology - ASET 2015 Copyright $\odot$ Institute of Research Engineers and Doctors, USA .All rights reserved.

ISBN: 978-1-63248-084-2 doi: 10.15224/ 978-1-63248-084-2-93 